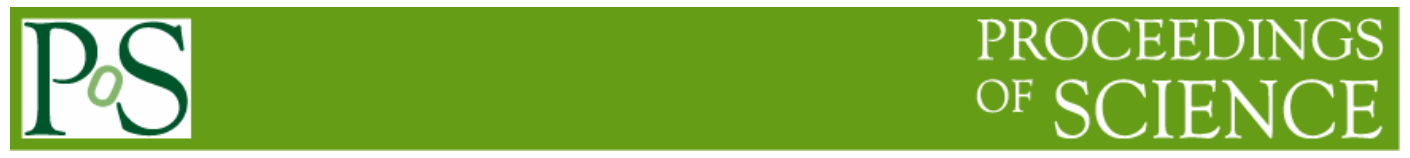

\title{
In Memory of John Bahcall and Ray Davis
}

\section{Peter Parker}

Yale University

272 Whitney Avenue, New Haven, CT, USA

E-mail: peter .parker@yale.edu

International Symposium on Nuclear Astrophysics - Nuclei in the Cosmos - IX

CERN, Geneva, Switzerland

25-30 June, 2006 
I first met John in 1962 when he arrived at Caltech as a young post-doc, brought to Kellogg by Willy Fowler on the basis of the very perceptive piece of work which John had just carried out looking at nuclear electron-capture rates in stellar plasmas-with particular implications for the decay of ${ }^{7} \mathrm{Be}$ in the sun. (At the time I was still a graduate student, only slightly younger than John, but still working hard to finish up my thesis on the production of ${ }^{7} \mathrm{Be}$ in the sun.)

Most probably, this was not at all what John would have had in mind for his future 10 years earlier when he was entering Louisiana State as a freshman-already a high school state tennis champion and aiming towards the study of philosophy and perhaps a career as a Rabbi. But, within a year, he had "discovered” physics and transferred to UC Berkeley—graduating from there in 1956 as a physics major with his eyes firmly fixed on the astrophysical study of the Cosmos that would occupy his entire professional career. Following the completion of his $\mathrm{PhD}$ thesis at Harvard in 1961, John moved to Indiana to study the weak interaction with Emil Konopinski, and this led to the insightful work that caught Willy's attention and led to John's move to Pasadena in 1962.

An early product of John's immersion into the environment of Kellogg was this brief paper which John with his twinkling sense of humor would later refer to (on the basis of a reordering of the authors' names) as FIBS because of how much they really didn't yet know about neutrinos and their production and detection-such as the role that would be played in the ${ }^{37} \mathrm{Cl}$ detector by the superallowed transition to the $\mathrm{T}=3 / 2$ isobaric analog state in ${ }^{37} \mathrm{Ar}$, something which John would recognize just a year later, in 1964.

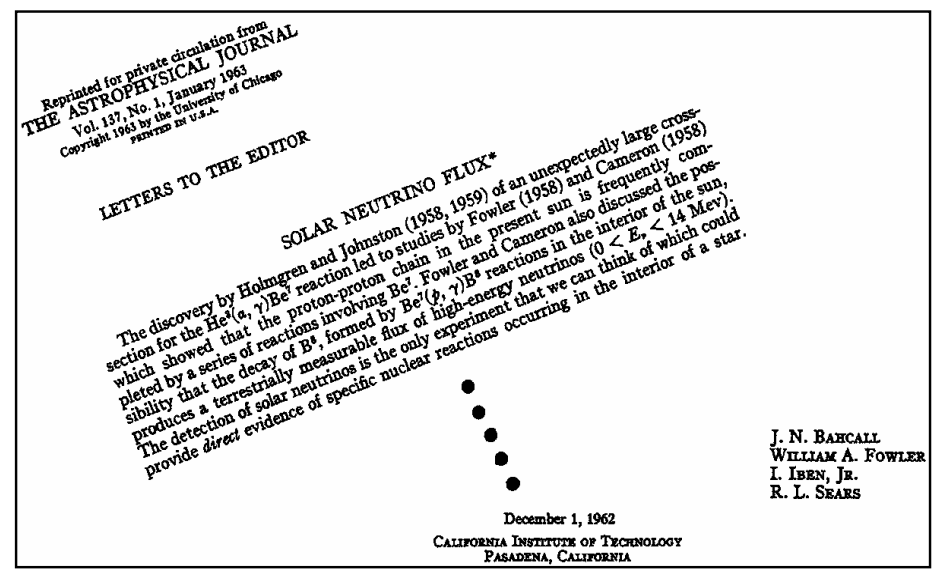

Figure 1. Ap. J. 137 (1963) L344.

(Note the reference in

the second line to $\mathrm{Al}$ Cameron's work on the role of ${ }^{7} \mathrm{Be}$ in the termination of the proton-proton chain.)

From the beginning of John's early years at Kellogg, Willy encouraged John's work with Ray Davis who was then at Brookhaven working on the chemistry of detecting neutrinos through the conversion of ${ }^{37} \mathrm{Cl}$ to ${ }^{37} \mathrm{Ar}$. And thus began the wonderfully close, lifelong friendship and collaboration between these two incredibly warm and generous human beings. An early output from their work was this pair of 1964 Phys. Rev. Letters outlining Ray's proposed ${ }^{37} \mathrm{Cl}$-detector experiment and what it would mean.

The Homestake Detector was approved shortly thereafter, and here we see Ray and John down in the mine in 1966 or 1967 as the chlorine tank was being assembled and welded together. (John's caption for this picture in a later review article comments that "This picture has been useful in explaining what a neutrino theorist actually does.”) 


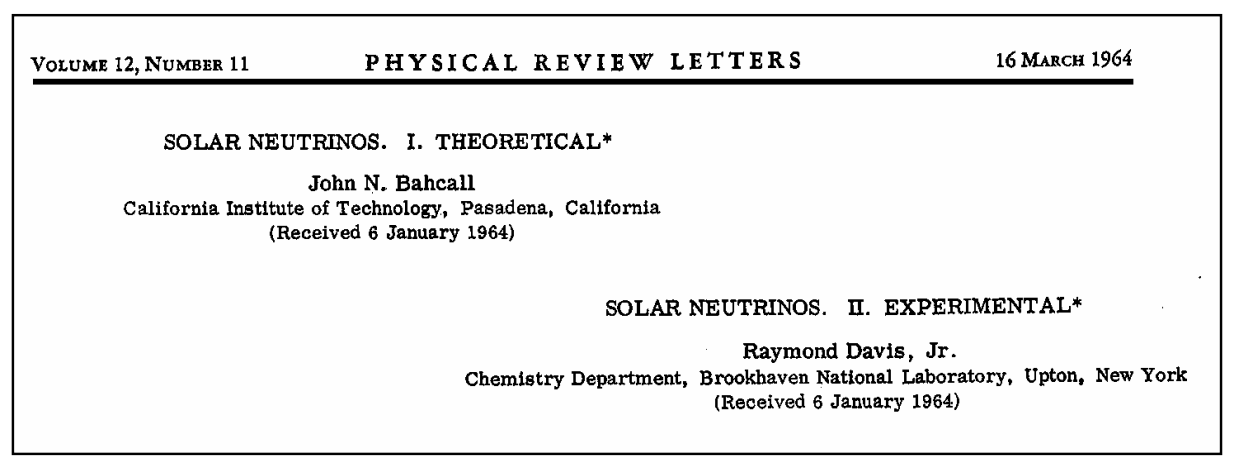

Figure 2. Phys. Rev. Letters 12 (1964) 300 and 303.

In Figure 4, for balance, we see what a neutrino experimentalist actually does-Ray carefully putting his few precious ${ }^{37} \mathrm{Ar}$ atoms into a battleship gun barrel which provided some of the shielding for his early counters. When it became clear that Ray wasn't finding the "expected" number of ${ }^{37} \mathrm{Ar}$ atoms, and the first results were published in another pair of Phys. Rev. Letters in 1968 (giving birth to the *Solar Neutrino Problem*) John used to delight in relaying the story of how sympathetic miners at Homestake had tried to console Ray by reassuring him that it had been an unusually cloudy summer. A year later, in 1969, John (a theorist, after all) was working to cover his bets-already calculating the effects of neutrino vacuum oscillations.

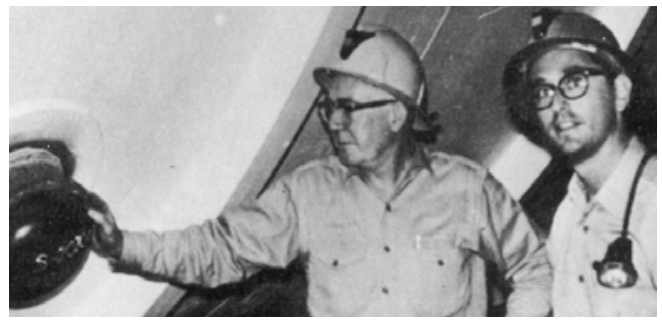

Figure 3. John and Ray in the Homestake mine in 1966-67.

John's and Ray's persistent and meticulous work on this problem was to continue for 3 more decades. For this work

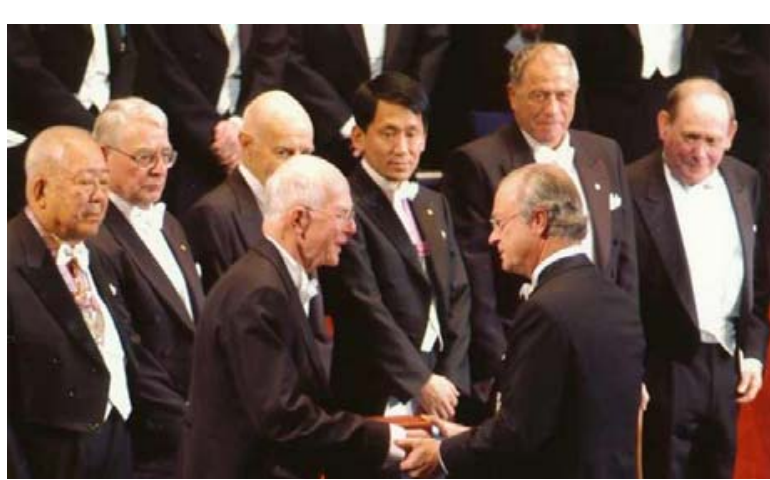

Figure 5. Ray receiving his Nobel Prize from King Gustaf.

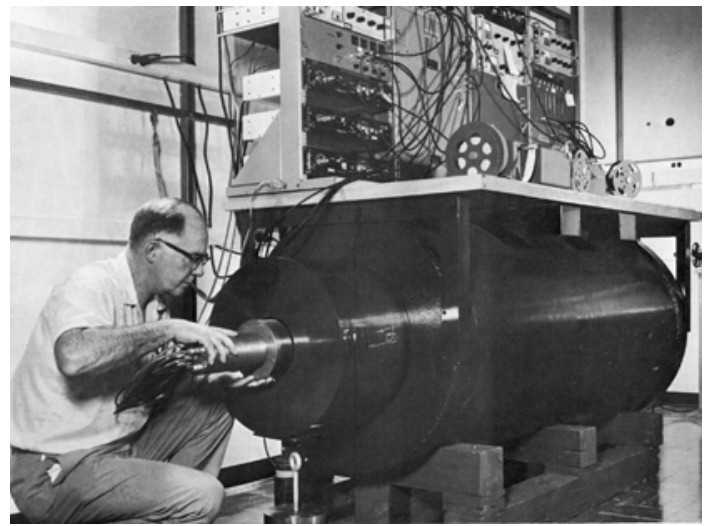

Figure 4. What a neutrino experimentalist actually does.

they would each be awarded the National Medal of Science - John in 1998 and Ray in 2002, the same year in which Ray also won the Nobel Prize in Physics. And then, most appropriately, in 2003 they shared the DOE's Enrico Fermi prize.

Neta and their 3 children (Safi, Dan, and Orli) were always an enormously important and happy part of John's world. Here we see the family on 
the occasion of John's being awarded the National Medal of Science by Bill Clinton in 1998.

I still remember fondly a trip which John and Neta made to Yale in 1970 (shortly after moving to Princeton) - a day when John was the proud parent and babysitter, looking after Safi (who was still in his crawling stage - on the rug in Allan Bromley's

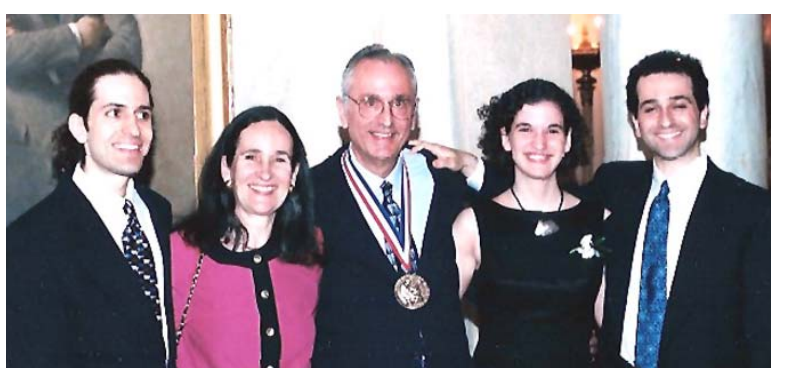

Figure 6. John, Neta, Safi, Dan, and Orli at the National Medal of Science ceremony in 1998.

office) while Neta spent the day checking out the measuring machines and blink comparators in the basement of the adjacent Astronomy building as part of a continuing research project. While I am in this familial vein, I would like to also note that tomorrow morning Andy Davis will present the lead-off talk in the session on the very fine work now being done on abundances in micron size Presolar Grains. Indeed, as they say, 'the acorn doesn't fall far from the oak tree'. This picture which Andy sent to me struck me as particularly symbolic and appropriate for Ray whose perseverance and patience meant that he was always focused on the long view of things.

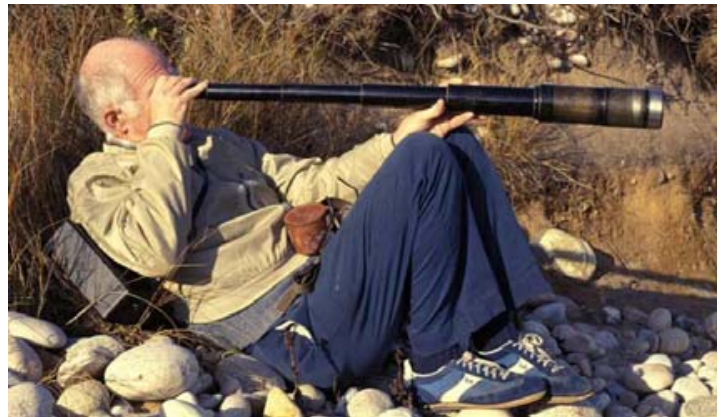

Figure 7. Ray taking the long view of things.

In closing, as we look here at the transition of John from his 1960 "Joe Cool" image as a graduate student to this classic image from much more recent years, I will simply note that it will come as no surprise to any of us who have worked with John over the years that 2 of the adjectives that came up time and again in the obituary comments both from his family and from his

close colleagues in the Solar Neutrino project and the Hubble Space Telescope project were "persistent" and "tenacious". John was an incredibly dedicated and perceptive scientist who could see where to look for the answers to important questions and who understood the importance of working hard to find those answers. Similarly, in Ray's obituary, it will come as no surprise to anyone who ever worked with Ray that in addition to his perseverance, Ken Lande commented that "Ray was the most optimistic person you could ever encounter. For Ray...the greater the challenge, the more fun it was to attack it."

John and Ray were indeed Special Scientists and Special Friends.

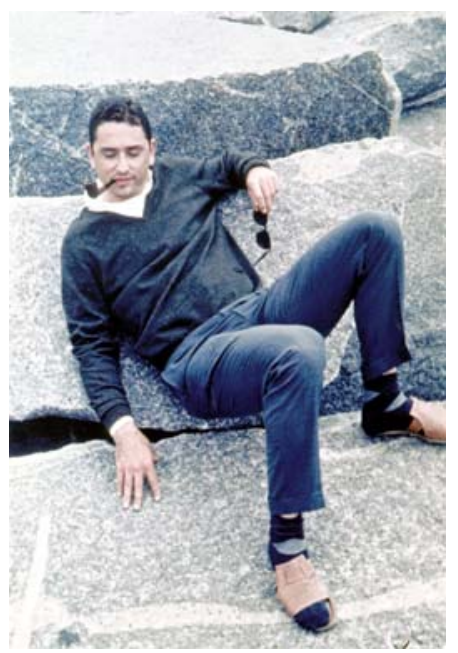

Figure 8. John as a graduate student in 1960 . 


\section{Acknowledgements}

With special thanks to Neta and Andy for allowing me to use these pictures of John and Ray.

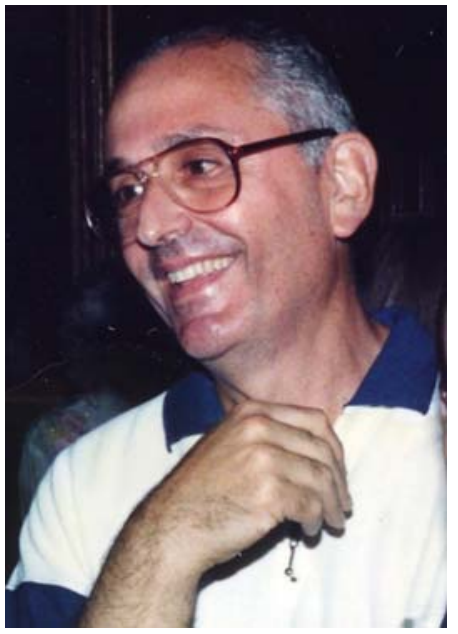

Figure 9. "No caption necessary.” 